Publicação organizada pelo Programa de

Mestrado Profissional Stricto Sensu em

Engenharia Civil da Universidade São Judas

Volume 03 - Edição 01

Janeiro - Dezembro de 2020

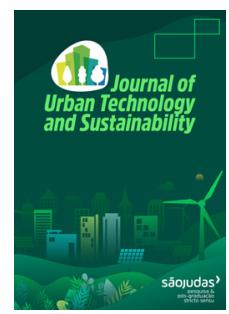

\title{
Discurso sustentável e a prática de remanejamento: Estudo de caso em intervenção habitacional do Programa de Aceleração do Crescimento em Belém (PA)
}

Marlon D. Castroa,

${ }^{a}$ Núcleo de Altos Estudos Amazônicos, Programa de Pós-Graduação em Desenvolvimento Sustentável do Trópico Úmido, Universidade Federal do Pará (NAEA/UFPA), Brasil.

\section{Informações}

Recebido 20 Outubro 2020

Manuscrito revisado recebido

27 Novembro 2020

Aceito 1 Dezembro 2020

\section{Palavras-chave}

Discurso sustentável

Programa de aceleração de crescimento

Projeto de trabalho técnico social

\section{Resumo}

Remanejamentos urbanos têm sido as práticas mais comuns para reduzir a quantidade de assentamentos precários vulneráveis do ponto de vista socioambiental na Região Metropolitana de Belém nas últimas décadas, mas seus resultados e efetividade ainda são discutíveis. Este artigo procura analisar as interpretações discursivas e aproximações ao conceito de sustentabilidade urbana em uma intervenção de habitação de interesse social oriunda do Programa de Aceleração do Crescimento (PAC) em Belém (PA), a partir do Projeto de Trabalho Técnico Social (PTTS), visando estabelecer nexos de sustentabilidade entre a população atendida pelo Programa durante a realização das obras da intervenção - o Projeto Taboquinha, localizado no distrito de Icoaraci. Foi utilizada pesquisa qualitativa a partir dos projetos técnicos, documentos, além de entrevistas semiestruturadas com técnicos elaboradores e executores. Percebe-se que em relação à sustentabilidade, tomando por base a categoria lazer, foco do estudo, o Projeto reproduz espaços sem relação com as vivências materiais e substantivas dos sujeitos atendidos, desconsiderando suas necessidades e práticas cotidianas.

\section{Sustainable discourse and the relocation practice: Case study in housing intervention of the Growth Acceleration Program in Belém (PA)}

\section{Article info \\ Received 20 October 2020 \\ Received in revised form 27 November 2020 \\ Accepted 1 December 2020}

\section{Keywords}

Sustainability

Growth acceleration

program

Technical social work

program

\begin{abstract}
Urban relocations have been the most common practices to reduce the number of socially and environmentally vulnerable precarious settlements in the Metropolitan Region of Belém in recent decades, but their results and effectiveness are still debatable. This article seeks to analyze the discursive interpretations and approaches to the concept of urban sustainability in a housing intervention of social interest originating from the Growth Acceleration Program (PAC) in Belém (PA), based on the Technical Social Work Project (PTTS), aiming to establish nexus of sustainability among the population served by the Program while carrying out the intervention works - the Taboquinha Project, located in the Icoaraci district. Qualitative research was used based on technical projects, documents, as well as semi-structured interviews with technical writers and executors. It can be seen that in relation to sustainability, based on the leisure category, the focus of the study, the Project reproduces spaces unrelated to the material and substantive experiences of the subjects served, disregarding their needs and daily practices.
\end{abstract}

\section{Discurso sostenible y práctica de relocalización: estudio de caso en intervención habitacional del Programa de Aceleración del Crecimiento en Belém (PA)}

\section{Información}

Recibido 20 Octubre 2020

Manuscrito revisado recibido 27 Voviembre 2020

Aceptado 1 Diciembre 2020

\section{Palabras clave}

Discurso sostenible

Programa de aceleración del crecimiento

Proyecto de trabajo técnico social

\section{Resumen}

Las reubicaciones urbanas han sido las prácticas más comunes para reducir el número de asentamientos precarios social y ambientalmente vulnerables en la Región Metropolitana de Belém en las últimas décadas, pero sus resultados y efectividad aún son discutibles. Este artículo busca analizar las interpretaciones y enfoques discursivos del concepto de sustentabilidad urbana en una intervención habitacional de interés social originada en el Programa de Aceleración del Crecimiento (PAC) en Belém (PA), con base en el Proyecto Técnico de Trabajo Social (PTTS), con el objetivo de establecer nexos de sustentabilidad entre la población atendida por el Programa durante la ejecución de las obras de intervención - Proyecto Taboquinha, ubicado en el distrito de Icoaraci. Se utilizó investigación cualitativa basada en proyectos técnicos, documentos, así como entrevistas semiestructuradas con redactores técnicos y ejecutores. Se puede observar que en relación a la sustentabilidad, a partir de la categoría de ocio, el foco del estudio, el Proyecto reproduce espacios ajenos a las vivencias materiales y sustantivas de los sujetos atendidos, desconociendo sus necesidades y prácticas diarias.

\footnotetext{
* Autor correspondente em: Núcleo de Altos Estudos Amazônicos, PPG em Desenvolvimento Sustentável do Trópico Úmido, UFPA.

E-mail: marloncastro@ufpa.br (Marlon. D. Castro)
} 


\section{Introdução}

A temática da sustentabilidade tem sido evocada, com frequência, de modo a fazer as expectativas de bem-estar transitarem dos âmbitos da habitação, da saúde e dos direitos sociais, fortemente marcados pelo acesso socialmente desigual, para uma noção de meio ambiente construída como una e comum a todos (ACSELRAD, 2005). Revestido, assim, dessa roupagem sustentável universalista, o meio ambiente convém aos propósitos de construção de um consenso social destinado a reconstituir, em um mundo socialmente fragmentado, o sentido de comunidade, solidariedade e interesse comum, buscando acomodar as diferenças em uma nova totalidade interdependente.

Acselrad (2009) pontua que a busca de um consenso urbano de tal forma ampliado espacial e temporalmente, legitimado nos propósitos do equilíbrio biosférico e da justiça intergeracional, explica-se pela necessidade de prevenção dos riscos de ruptura sociopolítica em cidades crescentemente fragmentadas pelos processos de globalização e acumulação flexível. Portanto, se o recurso à noção de sustentabilidade urbana parece integrar de forma crescente uma norma do planejamento aplicado a cidades fortemente divididas, o caráter simbólico das ações associadas a tal noção (seja pela representação retórica de um meio ambiente uno e consensual, seja pelo sentido que se queira imprimir às operações materiais "de conexão", empreendidas em seu nome) não parecerá suficiente para dar estabilidade aos mecanismos da reprodução urbana. A noção de sustentabilidade parecerá, assim, constituir apenas parte de um esforço mais amplo de configurar um novo modo de regulação urbana capaz de integrar duravelmente na dinâmica reprodutiva a própria desigualdade constitutiva das cidades.

É neste contexto que está inserido o Programa de Aceleração do Crescimento (PAC), programa estatal anticíclico que foi colocado em prática pelo governo brasileiro na segunda metade da década passada, com vistas a diminuir os efeitos da crise mundial surgida nos Estados Unidos, mas reverberada em escala planetária. O PAC consolidou-se como estratégia de ampla ação de movimentação econômica, principalmente ligada à construção civil nos grandes centros urbanos do país, estando dividido em eixos de atuação que vão desde o saneamento até a construção de unidades habitacionais. Com o PAC, dá-se continuidade à estratégia de substituição das áreas de baixadas belenense por conjuntos habitacionais, processo este que vem acontecendo nas últimas três décadas, ora ligado a remanejamentos, ora objetivando reassentamentos de famílias em outros espaços da malha urbana metropolitana.

Neste artigo, é analisado o discurso de sustentabilidade presente em um projeto de habitação de interesse social do PAC, referente ao eixo Urbanização de Assentamentos Precários, destinado ao remanejamento e ao reassentamento de famílias em situação de risco e vulnerabilidade socioambiental em Belém (PA).

A metodologia utilizada está centrada na análise qualitativa do Projeto de Trabalho Técnico Social (PTTS), referente às intervenções habitacionais do Projeto Taboquinha: conjuntos habitacionais Cruzeiro, Mestre Cardoso e Mestre Verequete, localizados no distrito de Icoaraci, em Belém, além de entrevistas semiestruturadas com técnicos responsáveis pela elaboração, execução e fiscalização das intervenções habitacionais, todas elas vinculadas à Companhia Executiva de Habitação do Pará (COHAB), além de entrevistas com chefes de família beneficiários do Programa. Este artigo está relacionado ao tema da tese de doutorado do autor, que analisa discursos de sustentabilidade presentes nas intervenções habitacionais de interesse social para remanejamento e reassentamento urbanos na Região Metropolitana de Belém, ora em desenvolvimento.

\section{Sustentabilidade e prática de remaneja- mento}

Entre vários termos derivados da ideia de desenvolvimento sustentável, um dos mais difundidos é o da sustentabilidade. O sentido semanticamente criado permite pensarmos na durabilidade e na continuidade de recursos e ações que impedem o esgotamento das condições de 
produção e reprodução social, criando um sentido de permanência em termos civilizatórios que os termos anteriormente consolidados sobre o tema não dispunham.

No entanto, ao apontar uma direção para a superação dos problemas ambientais, a sustentabilidade pode, ao contrário, estar mais do que apontando uma solução, mas induzindo à construção de um senso comum em torno dessa direção. Apontando uma saída, a ideia de sustentabilidade atua no sentido de criar uma falsa ideia de que este seria o único caminho possível para evitar um desastre ambiental planetário.

Acselrad (2009) diz que a associação da noção de sustentabilidade à ideia de que existe uma forma social durável de apropriação e o uso do meio ambiente dada pela própria natureza das formações biofísicas significa, por exemplo, ignorar a diversidade de formas sociais de duração dos elementos da base material do desenvolvimento. A construção de um caminho para a crise ambiental baseado na ideia de continuidade das coisas (recursos e atitudes) como elas são e sua apresentação como o único caminho a ser tomado devem ser entendidas como a construção de um conceito que busca preservar as estruturas produtivas, relações sociais, as estruturas políticas. Não se pode, portanto, aceitar a ideia de sustentabilidade como um remédio dado para os males ambientais em todos os níveis. É preciso reconhecer que existem várias maneiras de as coisas durarem, como lembra Acselrad.

O discurso da sustentabilidade foi a matriz conceitual por trás dos instrumentos legais criados no Brasil nos últimos anos para permitir uma apropriação privada cada vez maior dos recursos naturais, apresentando-se, por exemplo, na associação entre preservação ambiental e qualidade de vida, esta entendida como uma vida em harmonia com a natureza longe da poluição, o que deveria ser um valor universal, mas que, na prática, precisa ser adquirida como uma mercadoria, submetida como um valor de troca, pura e simplesmente. A sustentabilidade transformou a natureza numa commodity a ser explorada e dissolvida pelo capital. Neste sentido, a sustentabilidade revela seu lado mais perverso, uma vez que, num cenário de enormes desigualdades sociais, como o das grandes cidades brasileiras, só uma minoria das pessoas tem condições de experimentá-la, justamente pelo fato de que, no caso brasileiro, as discussões ambientais mundiais foram assimiladas sem que houvesse equacionamento das questões sociais (PRADO, 2015). Deste modo, para a maioria da população urbana do Brasil, para quem nenhum desenvolvimento concreto foi oferecido até hoje, a sustentabilidade parece um sonho muito distante.

A ideia de "desenvolvimento urbano sustentável" pode ser considerada de antemão uma contradição em termos, como aponta Costa (2006). Isso porque a expressão tenta conciliar o que é aparentemente inconciliável, o crescimento da cidade e sua qualificação ambiental. Essa ideia surgiu entre o final dos anos de 1980 e início dos anos de 1990, no contexto geral de consolidação do conceito geral de desenvolvimento sustentável, em um momento em que dois campos distintos tentam fazer convergir seu pensamento, apesar de suas origens e objetivos completamente diferentes: o campo da análise ambiental e o campo da análise urbana. Essa aproximação foi amadurecida ao longo de muitos anos durante os quais os estudos ambientais dentro das competências do planejamento urbano permaneceram restritos a nichos técnicos, enquanto estudos urbanos dentro do campo das ciências ambientais praticamente inexistiam (COSTA, 1999).

Questões ambientais urbanas, como o saneamento das cidades, foram durante muito tempo tratadas relativamente à eficiência, com base muito mais numa racionalidade técnico-científica do que em termos ambientais, numa perspectiva mais ampla e sistêmica. A visão integrada entre as diversas questões ambientais urbanas ainda é pouco comum no universo do planejamento urbano estatal brasileiro, por isso, em limites institucionais, o conceito de "desenvolvimento urbano sustentável" sempre esbarrou na divisão política e administrativa em que são acomodadas as principais questões ambientais e urbanas.

Nas últimas décadas, entretanto, o conceito de sustentabilidade vem sendo atrelado a uma 
forma hegemônica de pensar a sociedade e a natureza, ignorando as determinações históricas do processo produtivo capitalista, essencialmente destrutivo, permanecendo radicado muito mais como uma ideologia que unifica os interesses dos trabalhadores, dos empresários e do Estado em torno da defesa de uma pretensa sustentabilidade ambiental, social e econômica (PRADO, 2015).

Costa (1999) destaca quetratar desustentabilidade urbana, ou mesmo buscar definições sobre o que representa o conceito de sustentabilidade, apresenta-se como uma tarefa complexa e, por vezes, contraditória. Essa dificuldade se deve, em parte, à banalização do termo em razão de seu emprego contínuo como viés publicitário por grandes empresas multinacionais ou, então, por agências internacionais que o incluem no bojo de interesses particulares e que pouco tem a ver com a conciliação entre preservação do meio ambiente e objetivos de desenvolvimento.

Percebe-se que outro segmento tem se concentrado em usar o termo com foco unicamente na sua dimensão ecológica, sem se preocupar em contemplar as necessidades humanas. Por outro lado, a aplicação do conceito à dimensão urbana traz consigo conflitos teóricos de difícil conciliação. Esses conflitos tendem a se concentrar em duas direções: uma que envolve a trajetória da análise ambiental e da análise urbana, as quais se originaram de áreas do conhecimento diferentes, mas convergem na proposta de um desenvolvimento urbano sustentável; e outra mais restrita à dimensão prática, em que se verifica um distanciamento entre formulações teóricas e propostas de intervenção (COSTA, 1999).

Em relação às políticas habitacionais, percebe-se que o elemento sustentabilidade é muito propalado, inclusive existindo certificações nacionais e internacionais para sua mensuração no ambiente construído, especificamente criadas para avaliar a sustentabilidade em projetos, desde a elaboração do projeto técnico até o pós-ocupação, o que, no entanto, não garante a consolidação da conexão entre a intervenção, as necessidades da população atendida e a cidade (CEF, 2010).

A inserção qualitativa dos projetos e famílias na malha urbana é problemática, principalmente por alterações no modo de vida. Relações com o espaço e com o mundo do trabalho também necessitam atenção, pois vão de encontro a qualquer interpretação do conceito de sustentabilidade urbana. Especificamente no que tange à RMB, existem importantes lacunas a serem preenchidas sobre a discussão entre política habitacional concebida nas últimas décadas para remanejamento e reassentamento, essencialmente visando à superação dos problemas de saneamento das "baixadas" (CASTRO, 2013; LEÃO; LIMA, 2017).

Diante da ambiguidade da atuação do setor público no que se refere à implementação de políticas urbanas comprometidas com a sustentabilidade, há, em Belém e região, uma forte concorrência das estratégias de uso e ocupação do solo impostas pelo capital imobiliário. Ao mesmo tempo, a RMB é apresentada como a região metropolitana brasileira com maior extensão de assentamentos precários (IBGE, 2010), que, em grande medida, correspondem às áreas "de baixada"1 que foram ocupadas informalmente e guardam uma articulação de origem com a tradição ribeirinha (CARDOSO; VENTURA, 2013).

Ainda que o espaço produzido informalmente tenha limitações e precariedades (ruas estreitas, carência de infraestrutura, adensamento excessivo), ele garante aos seus moradores efetiva mobilidade por meio de transporte público e bicicleta, ou mesmo a pé. Apresenta, ainda, diversidade de usos, boa conexão com a cidade formal e oportunidades de geração de renda, todos estes, aspectos positivos quando se consideram o espraiamento e o consumo energético como fatores de insustentabilidade. O fato de não ter havido planejamento prévio foi compensado pela natureza gradual da ocupação e das melhorias realizadas, o que permitiu que sua população original pudesse permanecer na área (CARDOSO; VENTURA, 2013).

Historicamente, a ausência de alternativas

1 As baixadas belenenses seriam uma forma de assentamento informal própria da cidade amazônica, na qual o pobre urbano utiliza estratégias de sobrevivência na cidade ligadas as suas referências regionais. É relevante nas baixadas a presença de aspectos culturais tanto na ocupação física como na dinâmica econômica e forma como as redes sociais são estabelecidas (LEÃO, 2017). 
habitacionais para a maior parte da população de baixa renda das grandes e médias cidades brasileiras condicionou que essa população se instalasse em espaços irregulares, do ponto de vista jurídico, e precários, do ponto de vista ambiental: ocupações informais, loteamentos irregulares, áreas alagadiças e/ou inundáveis, íngremes etc., áreas geralmente protegidas por lei e desprezadas pelo mercado imobiliário, o que tornou grande parte da população destas cidades passível a risco ambiental e social (ACSELRAD, 2009).

Há urgência na superação do contexto de exclusão e risco dessa população historicamente apartada da cidade e de seus benefícios. Medidas que regularizem estes assentamentos informais, possibilitando a inserção de equipamentos urbanos, infraestrutura e serviços visando a reduzir a vulnerabilidade social e ambiental de comunidades e populações devem ser vistas como prioritárias (MARICATO, 2005; UN-HABITAT, 2009). Em algumas áreas, entretanto, onde há a impossibilidade de realização de melhorias devido ao fato de oferecerem risco à saúde e à vida, segundo a recomendação técnica e legal, são necessárias ações de reassentamento.

O Ministério das Cidades (MCIDADES) denomina reassentamento como alteração do local de moradia de famílias, implicando sua remoção para outro terreno, fora do perímetro do assentamento precário que está sendo urbanizado.

"Reassentamento trata-se da produção de novas moradias de diferentes tipos (apartamentos, habitações evolutivas, lotes urbanizados) destinadas aos moradores removidos de assentamentos precários não consolidáveis ou que habitam assentamentos consolidáveis com remoção" (MCIDADES, 2010, p. 26).

O reassentamento é a medida mais drástica a ser tomada em situações de populações em risco, ocorrendo excepcionalmente quando o assentamento não é consolidável, por encontrarse em áreas de risco, seja de inundações urbanas, desmoronamento ou outras (ABIKO; COELHO,
2009; MCIDADES, 2010; ROLNIK et al. 2011).

O remanejamento, por sua vez, para o Ministério das Cidades (2010), trata-se da

\begin{abstract}
“...] manutenção da população (ou de grande parcela desta) no local da intervenção. É o caso, por exemplo, de áreas que necessitam de troca de solo ou aterro, nas quais a solução é a remoção temporária das familias, a execução de obras de infraestrutura e construção de novas moradias neste mesmo terreno. A intervenção, neste caso, também envolve a abertura de sistema viário, implantação de infraestrutura completa, parcelamento do solo, construção de equipamentos (quando necessária) e a regularização fundiária" (MCIDADES, 2010, p. 24-25).
\end{abstract}

Assim, as terminologias "remanejamento" e "reassentamento", são utilizadas para definir o processo de deslocamento de populações. O curso Ações Integradas de Urbanização de Assentamentos Precários (MCIDADES, 2010) destacou que esses termos ainda podem ser equiparados aos de relocação e realocação.

Os reassentamentos e remanejamentos não podem ser arbitrários, seguindo interesses de mercado. Devem, sim, ser baseados no direito à cidade e no direito à moradia, utilizados sempre como última opção, quando nenhuma intervenção de infraestrutura, como macrodrenagem ou obras de contenção, por exemplo, for capaz de reduzir os riscos a que a população esteja sujeita (UN-HABITAT, 2012). Para Maricato (2003), o grande desafio das políticas urbanas e ambientais brasileiras no século XXI é justamente aliar a democratização da produção de novas moradias ao acesso à moradia legal e à cidade com todos os seus serviços e com infraestrutura e, nesse ponto, o acesso ao solo urbano constitui aspecto fundamental para uma cidade mais justa.

Reassentamentos e remanejamentos, pela sua efetivação, dizem estar conectados a algum sentido de sustentabilidade urbana e condizerem com a superação de um quadro de vulnerabilidade socioambiental que não é privilégio apenas do Brasil e da RMB. 
Cotidianamente, a população de mais baixa renda habitante das grandes cidades da América Latina, não coincidentemente a de maior vulnerabilidade social e ambiental, também está sujeita aos riscos de inundações, escorregamentos de encostas, convivência com resíduos perigosos, entre outras situações. Jacobi (2004) ressalta que não se pode negar a estreita relação entre riscos urbanos e o uso e ocupação do solo na cidade, pois nesta "é onde se delineiam os problemas ambientais de maior dificuldade de enfrentamento".

A localização das habitações dentro das cidades relaciona-se diretamente ao acesso ao solo urbano, de modo que as residências ocupantes de áreas menos privilegiadas, do ponto de vista físico, podem ser expostas a maiores ou menores riscos ambientais, sociais, de saúde, entre outros. Dessa maneira, os riscos estão intimamente ligados à espacialidade urbana que, em casos como o de Belém, denotam vulnerabilidade socioambiental e histórico de segregação socioespacial. A atuação governamental sobre o solo urbano é de fundamental importância para a compreensão dos limites e das possibilidades das estratégias ditas sustentáveis em uma metrópole que possui características muito peculiares de formação socioespacial e tratamento da precariedade ambiental ainda descolada dos aspectos sociais, tal como a habitação.

\section{O Programa de Aceleração do Crescimen- to (PAC)}

Objeto empírico deste estudo, o Programa de Aceleração do Crescimento (PAC), foi criado em 2007 com o objetivo de retomar o planejamento e a execução de grandes obras de infraestrutura social, urbana, logística e energética do país, "contribuindo para o seu desenvolvimento acelerado e sustentável" (MCIDADES, 2017). Foi pensado como uma estratégia para resgate do planejamento e retomada dos investimentos em setores estruturantes do país, a fim de contribuir para o aumento da oferta de empregos e a geração de renda, principalmente no setor da construção civil, elevando o investimento público e privado em obras consideradas estratégicas.
Na área de habitação, os investimentos do PAC têm como objetivo promover o acesso à moradia a partir da atuação em três eixos: Programa Minha Casa Minha Vida, Urbanização de Assentamentos Precários (UAP) e financiamento habitacional pelo Sistema Brasileiro de Poupança e Empréstimo (SBPE). São investimentos realizados em parceria com governos estaduais, municipais, entidades urbanas e rurais e setor privado (MPOG, 2016).

Estudar o PAC como política habitacional que teoricamente visa à superação da informalidade e, principalmente, da vulnerabilidade socioambiental com a diminuição de áreas de risco nas grandes cidades não tem relação apenas com a interpretação das noções de sustentabilidade, mas, antes, com a superação da desigualdade social. A transição vivida pelas famílias atendidas pelo PAC entre dois universos distintos é complexa e permeada por alterações nas relações desses sujeitos com o espaço produzido, com o lugar e com a cidade. Estas alterações não ocorrem apenas na dimensão simbólica, mas principalmente na materialidade das relações com o entorno das intervenções, com o trabalho, a mobilidade urbana, entre outras práticas sociais importantes para sua reprodução.

O PAC foi anunciado como um pacote de expansão da economia brasileira, com a retomada de investimentos em moradia e infraestrutura social, por meio de grande número de projetos visando à melhoria de espaços metropolitanos geridos pelo Governo Federal em parceria com estados e municípios. Destacam-se, entre suas diretrizes gerais, a priorização de investimentos em áreas de risco, de insalubridade e degradação ambiental, cuja demanda se sobreporia, em tese, à localização de áreas de precariedade infraestrutural e pobreza urbana (LEITÃO, 2009; LIMA et al., 2007).

O Programa é composto por um conjunto de medidas de médio e longo prazo, que integra ações em três "eixos estratégicos": infraestrutura social e urbana, infraestrutura logística e infraestrutura energética (BRASIL, 2010). Parte expressiva dos recursos destinados à chamada "infraestrutura social e urbana" foi direcionada para a recuperação de áreas ambientalmente degradadas e, mais especificamente, para ações relativas à urbanização 
de assentamentos precários, outrora viabilizados através de programas como o Crédito Solidário e o Pró-Moradia, bem como por linhas de financiamento como o Projeto Prioritário de Investimento (PPI) para intervenções em favelas, carro-chefe do PAC desde o seu início (CARDOSO, 2009).

Segundo dados do Ministério do Planejamento Orçamento e Gestão (MPOG) de 2016, os projetos PAC-UAP, na RMB, estavam majoritariamente localizados em Belém: 15 projetos iniciados, dos quais 10 contratados pelo Governo do Estado do Pará e 5 pela Prefeitura Municipal de Belém (PMB). Deste total, havia, em dezembro de 2017, 6 projetos atrasados, 5 paralisados, 4 contratados (mas não iniciados) e, ainda, nenhum finalizado. 0 total previsto é de 7.476 unidades. O município de Ananindeua possui 3 projetos do PAC-UAP iniciados, todos contratados pela Prefeitura, prevendo-se a construção de 730 unidades, porém os projetos estavam paralisados (MPOG, 2016). A Tabela 1 lista as obras em Urbanização de Assentamentos Precários nos municípios de Ananindeua e Belém.

Desde 2007, foram realizados, pelo Governo do Estado do Pará e pelas prefeituras de algumas cidades abrangidas pelo PAC, na modalidade UAP, investimentos públicos que contemplam prioritariamente famílias de baixa renda com implementação de infraestrutura urbana e produção de unidades habitacionais (UH). A Figura 1 destaca as intervenções do PAC-UAP na RMB até o ano de 2016.

Os projetos PAC-UAP resultam, também, da existência prévia de projetos iniciados em outras linhas de financiamento, como o Pró-Moradia, que por ele foram incorporados. Assim, segundo estudo do IPEA/IDESP (2013), a decisão pelas áreas não foi resultado de "definições baseadas em planos setoriais, senão por diferentes conjunturas como a existência de outras intervenções já iniciadas ou a mobilização da população e articulação com representações de movimentos de moradia".

Tais projetos, ainda que apresentem grande dificuldade em sua implementação, representam a possibilidade de integração urbana e social de assentamentos precários, em sua maioria inseridos na malha urbana dos municípios e em localizações qualitativamente diferentes na perspectiva da reprodução social. Efetivamente, o número de unidades habitacionais previstas também é relevante, frente à quantidade de unidades que governo estadual e prefeituras foram capazes de produzir nas últimas décadas, com o bônus de aceleração de processos de consolidação das comunidades e maior acesso da população a serviços urbanos (LIMA; LEÃO, 2017).

Desse modo, compreende-se que o trajeto percorrido pelas famílias contempladas pelos projetos de reassentamento ou remanejamento (e, com ele, mudança de habitação, espaço físico, condições de vida e residência, relações com o espaço) é importante para a análise da sustentabilidade urbana, pois, em tese, esse trajeto refletiria um esforço institucional para superação das vulnerabilidades ambiental e social - históricas, no caso da RMB. No caso das intervenções do PACUAP, essa análise está intimamente relacionada à necessidade de contenção dos efeitos da Crise Mundial em escala nacional, subvertendo a lógica criada, de forma participativa até então, para a política habitacional de interesse social, tornandose uma política estratégica com primazia mais pela objetividade, e menos pela consideração à totalidade urbana.

\section{Materiais e métodos}

A pesquisa realizada teve como lócus, as intervenções realizadas e especificamente destinadas ao remanejamento de famílias em situação de vulnerabilidade socioambiental do Projeto Taboquinha, em Belém (PA). Essas intervenções são subprojetos que visam à provisão habitacional e que fazem parte de projetos do PAC contemplados no eixo da Infraestrutura Social e Urbana.

Optou-se por essas intervenções pelo fato de possuírem beneficiários reassentados de áreas precárias do ponto de vista ambiental e social da RMB; e pelo fato de as unidades terem sido entregues há mais de dois anos, o que caracteriza a consolidação das famílias nos espaços a seguir elencados: 
Tabela 1. Projetos PAC-UAP na RMB (Adaptado de MPOG, 2016).

\begin{tabular}{|c|c|c|c|c|c|}
\hline $\begin{array}{l}\text { Município } \\
\text { beneficiado }\end{array}$ & Proponente & Empreendimento & $\begin{array}{l}\text { Data de } \\
\text { seleção }\end{array}$ & $\begin{array}{l}\text { Investimento total } \\
\text { (em R\$ milhares)* }\end{array}$ & Estágio \\
\hline Ananindeua & Município & Urbanização Icuí & Dez/07 & 44.628.891,89 & Em obras \\
\hline Ananindeua & Município & $\begin{array}{l}\text { Urbanização - Nova Esperança e } \\
28 \text { de agosto }\end{array}$ & Dez/07 & $20.377,66$ & Em obras \\
\hline Ananindeua & Município & Urbanização Distrito Industrial & Dez/07 & $18.106,21$ & Em obras \\
\hline Belém & Estado & $\begin{array}{c}\text { Riacho Doce e Pantanal ( } 3^{a} \\
\text { etapa) }\end{array}$ & Ago/07 & $24.470,46$ & Em obras \\
\hline Belém & Estado & $\begin{array}{l}\text { Comunidade Pantanal } \\
\text { (Mangueirão) }\end{array}$ & Ago/07 & $27.134,94$ & Em obras \\
\hline Belém & Estado & $\begin{array}{l}\text { Urbanização Riacho Doce e } \\
\text { Pantanal ( } 2^{a} \text { Etapa) }\end{array}$ & Ago/07 & $19.745,50$ & Em obras \\
\hline Belém & Estado & $\begin{array}{l}\text { Urbanização Riacho Doce e } \\
\left.\quad \text { Pantanal ( } 1^{a} \text { Etapa }\right)\end{array}$ & Ago/07 & $12.859,94$ & Em obras \\
\hline Belém & Estado & $\begin{array}{l}\text { Urbanização - Igarapé } \\
\text { Taboquinha** }\end{array}$ & Ago/07 & $77.876,01$ & Em obras \\
\hline Belém & Estado & $\begin{array}{c}\text { Urbanização - Comunidade Fé em } \\
\text { Deus }\end{array}$ & Ago/07 & $22.723,45$ & Em obras \\
\hline Belém & Estado & $\begin{array}{l}\text { Urbanização - Comunidade } \\
\text { Pratinha (Distrito de Icoaraci)** }\end{array}$ & Ago/07 & $30.679,71$ & Em obras \\
\hline Belém & Estado & Urbanização - Liberdade & Nov/09 & $19.999,61$ & Em obras \\
\hline Belém & Estado & $\begin{array}{c}\text { Urbanização - Residencial } \\
\text { Liberdade I }\end{array}$ & Jan/08 & $21.859,62$ & Em obras \\
\hline Belém & Estado & $\begin{array}{c}\text { Provisão Habitacional - Sede do } \\
\text { município }\end{array}$ & Mai/08 & $135.754,51$ & Em obras \\
\hline Belém & Município & Urbanização - Portal da Amazônia & Ago/07 & $25.930,21$ & Em obras \\
\hline Belém & Município & $\begin{array}{c}\text { Urbanização - Vila da Barca - } \\
\text { Artur Bernardes }\end{array}$ & Nov/10 & $15.755,80$ & Em obras \\
\hline Belém & Município & $\begin{array}{l}\text { Urbanização - Estrada Nova - } \\
\text { Sub-bacia - bairros Jurunas, } \\
\text { Cidade Velha e Batista Campos }\end{array}$ & Dez/07 & $66.417,34$ & Em obras \\
\hline Belém & Município & $\begin{array}{c}\text { Urbanização - Vila da Barca - } 3^{a} \\
\text { etapa }\end{array}$ & Ago/07 & $68.957,38$ & Em obras \\
\hline Belém & Município & $\begin{array}{c}\text { Município Urbanização - Bacia do } \\
\text { Paracuri }\end{array}$ & Dez/07 & $68.763,36$ & Em obras \\
\hline Castanhal & Estado & $\begin{array}{c}\text { Urbanização - Comunidade } \\
\text { Providentinos }\end{array}$ & Out/07 & $7.694 .558,33$ & Concluído \\
\hline Marituba & Município & $\begin{array}{c}\text { Provisão habitacional - Bairro } \\
\text { Decouville }\end{array}$ & Mai/09 & $2.441 .700,00$ & Em obras \\
\hline $\begin{array}{l}\text { Santa Isabel do } \\
\text { Pará }\end{array}$ & Estado & $\begin{array}{c}\text { Urbanização - Residencial Jardim } \\
\text { das Garças }\end{array}$ & Ago/07 & $7.719 .202,04$ & Em obras \\
\hline
\end{tabular}

* Inclui investimento de 2007 a 2014.

** Não inclui o valor da provisão habitacional conjugada, que foi considerado em item específico.

Projeto Taboquinha (composto por três conjuntos habitacionais: Conjunto Mestre Verequete, Conjunto Mestre Cardoso e Conjunto Cruzeiro), localizado no bairro Cruzeiro, Distrito de Icoaraci, em Belém (figura 2). Nestes conjuntos foram reassentadas, em blocos verticais, 978 famílias que ocupavam as margens do Igarapé Cubatão, também em Icoaraci. Esses subprojetos de conjuntos habitacionais estão relacionados ao Projeto de Urbanização da Bacia do Paracuri, que contempla, além da construção de unidades habitacionais, a urbanização de toda a área externa ao residencial e prevê, ainda, a recuperação do Igarapé Cubatão.

Dentre todos os projetos PAC-UAP em execução ou contratados na RMB, os aqui elencados para comporem o objeto empírico desta pesquisa 


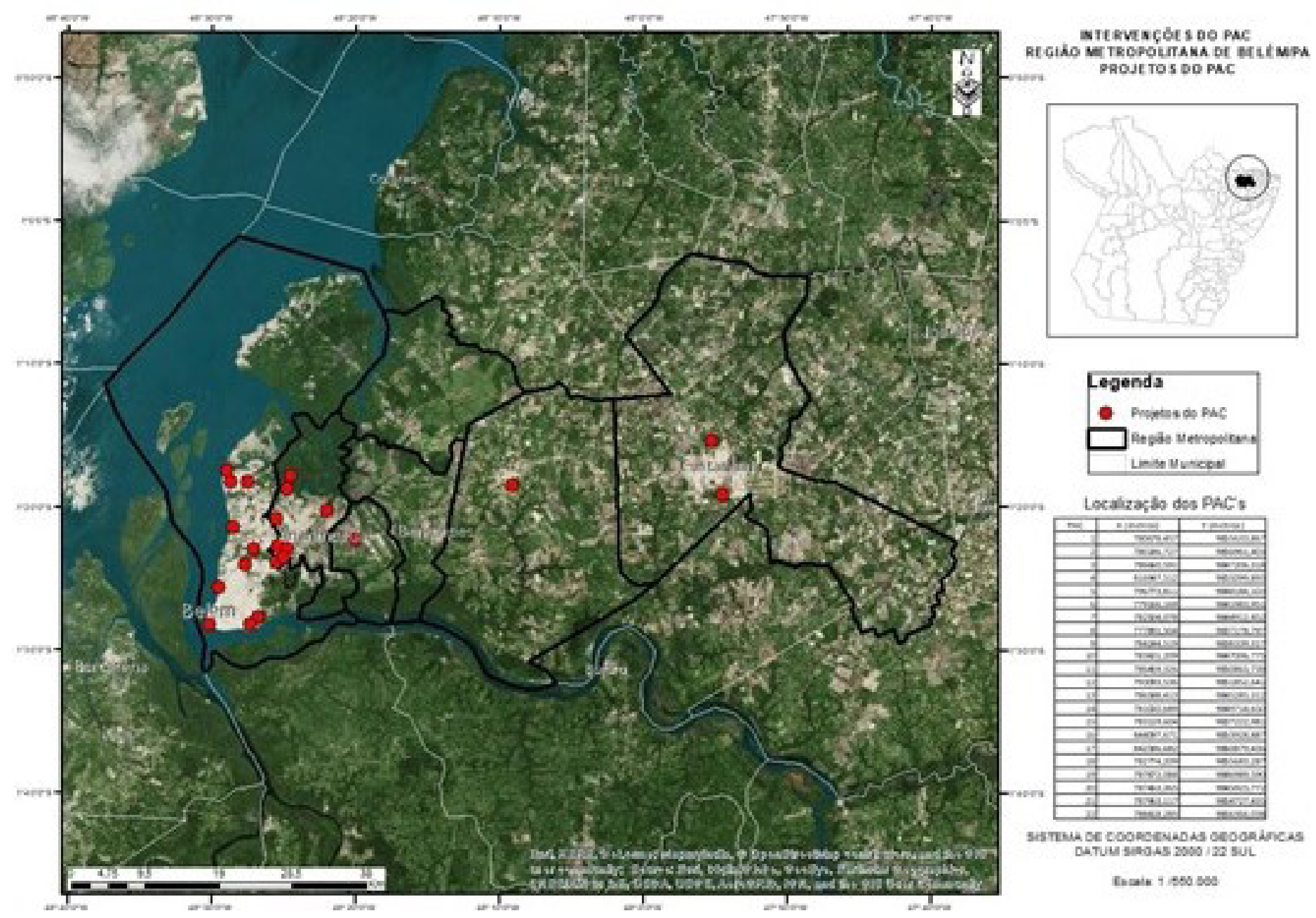

Fig. 1. Projetos PAC-UAP na RMB (adaptado de IBGE, 2012; MPOG, 2016).

correspondem a ações reassentamento e remanejamento, em que a transição entre espaços de habitação já ocorreu pelo menos em parte e em obediência aos critérios anteriormente destacados.

A abordagem metodológica deste estudo teve como preocupação captar e compreender os sujeitos sociais, em suas ações e relações, como produtores de sua existência material e social, por meio da utilização de abordagem qualitativa interdisciplinar ${ }^{2}$ sobre o Projeto de Trabalho Técnico Social (PTTS) de intervenções habitacionais pensadas para remanejamento e reassentamento de famílias de áreas de risco ambiental no Igarapé Cubatão, no distrito de Icoaraci, em Belém. Dessa

2 Para Japiassu (1976), o trabalho interdisciplinar propriamente dito supõe uma interação das disciplinas, uma interpenetração ou interfecundação, indo desde a simples comunicação das ideias até a integração mútua dos conceitos (contatos interdisciplinares), da epistemologia e da metodologia, dos procedimentos, dos dados e da organização da pesquisa. Para o autor, é imprescindível a complementação dos métodos, dos conceitos, das estruturas e dos axiomas sobre os quais se fundam as diversas disciplinas. O objetivo utópico do interdisciplinar é a unidade do saber. postura e concepção, derivaram os procedimentos metodológicos, técnicos e estratégicos utilizados nesta investigação.

Inicialmente foi solicitado o documento original do PTTS junto à Companhia Executiva de Habitação do Pará (COHAB), além de relatórios pós-ocupação das intervenções. Paralelamente, foram realizadas entrevistas semiestruturadas com técnicos diretamente envolvidos no planejamento, execução e avaliação dos PTTS e dos projetos físicos intervenções estudadas, além de entrevistas com beneficiários das ações, moradores dos conjuntos habitacionais que participaram desde o início na transição entre os espaços de ocupação irregular e vulnerável até o seu ingresso e consolidação nestas intervenções. Os entrevistados são identificados pelas letras "T", para técnicos, e "B", para beneficiários na análise dos dados.

Lefebvre (1977) identifica três dimensões da cotidianidade que, postas em relação dialética, 


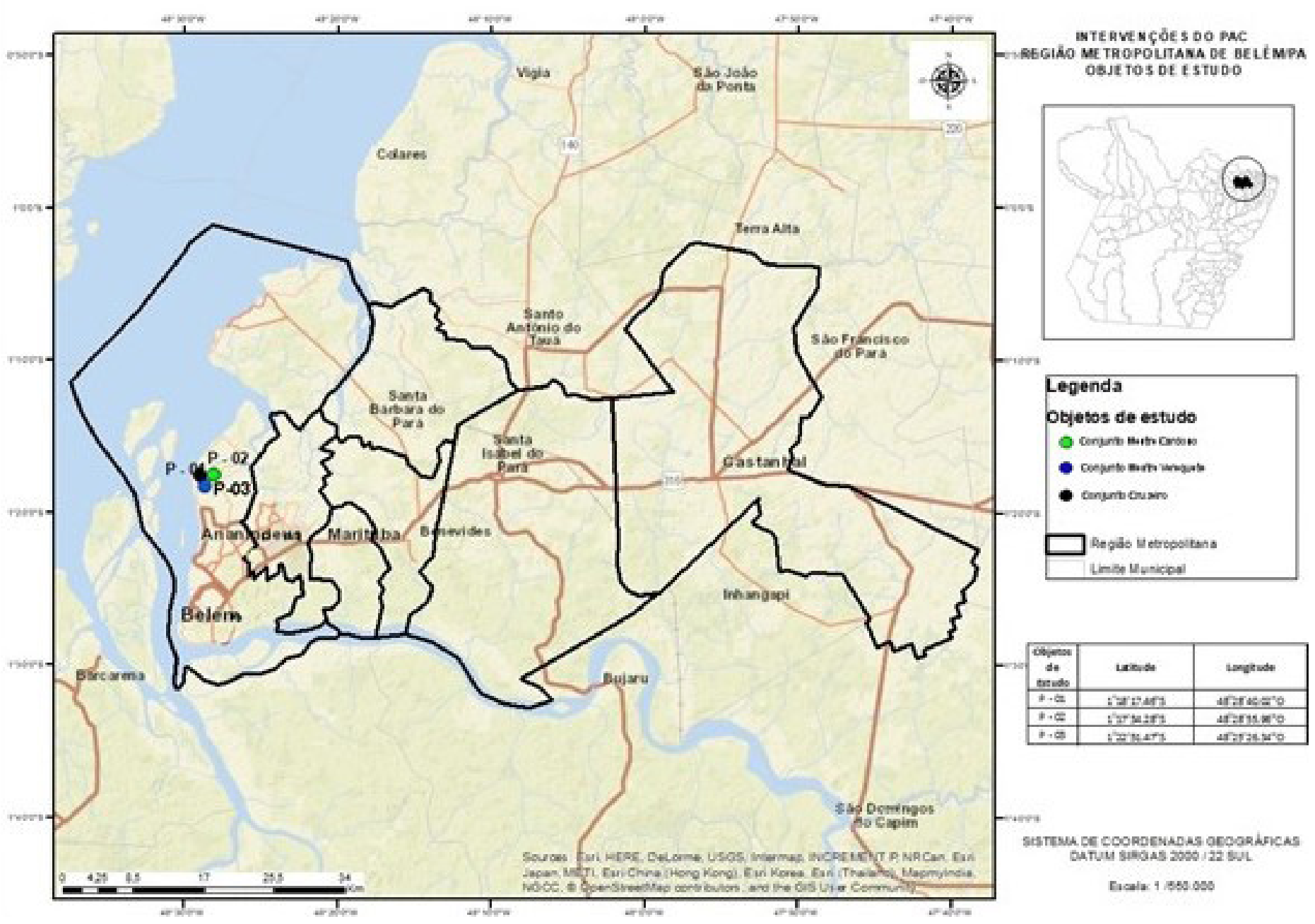

Fig. 2. Conjuntos Habitacionais do PAC-UAP objetos de estudo (adaptado de IBGE, 2010; IPEA/IDESP, 2014).

constituem uma unidade, portanto uma totalidade que deve ser apreendida. Essas três dimensões são o trabalho, a família e o lazer. Assim, o projeto lefebvriano supõe um estudo das possibilidades e limitações contidas nessas duas dimensões da existência social humana, a dimensão material e a dimensão social.

Nesse sentido, pensar o cotidiano na sua tripla dimensão (trabalho, família e lazer) é pensá-lo como uma esfera tensa da vida social carregada de conflitos. Esses três termos definem uma relação dialética em que as normas e os padrões de interação se contradizem ou se negam, eles também marcam, na sua estrutura, as possibilidades de existência concreta dos seres humanos. A ideia de que toda realização humana e de que toda integração social se dá pelo trabalho é contraposta à situação concreta dentro do modo de vida do moderno em que os projetos de vida, as aspirações, os desejos e sonhos de cada indivíduo envolvem essas três dimensões, isto é, o social como pressuposto da existência humana também se concretiza no lazer e na vida privada (familiar).

O uso da tríade dialética é essencial em nossa análise, pois, tal como Lefebvre (1977) acredita que o presente não esclarece o real, necessitando-se de regressão em busca de encontrar o marco da mudança, nosso percurso metodológico requer um esforço de reflexão cujo pano de fundo é o método dialético de investigação, pois nos faz enxergar que, por trás de toda a coerência que o modo de produção capitalista tenta passar, há um processo rico em contradição se desenvolvendo. Foi escolhida a categoria lazer para consolidar as análises aproximadas à sustentabilidade nesse artigo, compreendendo esta como uma esfera da vida social imprescindível para a comunidade.

Em síntese, trata-se de reconhecer onde se situam o antigo, o novo, o diferente, uma vez que é a relação dialética desses três movimentos que mantém a reprodução do sistema. O novo aparece, 
muitas vezes, como tendência, uma novidade que contém diferentes tempos históricos, mas que, ao ser investigado, pode oferecer os elementos para uma análise que contribua para desvendar a essência da transformação da realidade.

\section{Discurso sustentável e remanejamento de população em risco}

Para embasar o processo de remanejamento para os conjuntos habitacionais do Projeto Taboquinha foi feito um levantamento socioeconômico prévio com a população a ser atendida que demonstrou que quanto aos responsáveis pelas famílias entrevistadas, $75 \%$ eram do sexo feminino, a maioria (65\%) com idade entre 18 e 45 anos, quase que a totalidade (93\%) natural do estado do Pará, cujo estado civil predominante era união estável com filhos, com escolaridade mais incidente no ensino fundamental incompleto. Normalmente estas pessoas têm entre duas a três pessoas sob sua responsabilidade financeira e educacional.

Quanto aos dependentes dos responsáveis pelas famílias, $72 \%$ eram estudantes, na maioria dos casos classificados no ensino fundamental incompleto. Tem renda mensal predominante na faixa de 1 a 2 salários-mínimos, normalmente garantidos por apenas um membro da família, no geral, advinda de atividades classificadas como autônomas. Era comum a dependência do igarapé para a garantia da renda familiar, pois era verificada a presença de muitos trabalhadores autônomos (pescadores) na comunidade. Detectou-se que em $11 \%$ das famílias entrevistadas possuíam uma pessoa portadora de necessidades especiais, porém apenas 1\% depende do uso de cadeira de rodas. Era observado o predomínio de uma população jovem, pois apenas 16\% possuíam mais de 65 anos. Quanto à moradia das famílias, prevaleciam os que moravam na área há mais de 5 anos, em condição de casa própria, construídas em madeira, dispondo de mais de 5 cômodos em estado de conservação predominantemente precário, no geral utilizado somente para fins de moradia (COHAB, 2007).

A partir destes dados, o direcionamento dado aos objetivos e principalmente às ações do PTTS foi delineado. Nota-se que a sustentabilidade aparece como elemento chave entre aspectos físicos e sociais no PTTS do Projeto Taboquinha, onde as estratégias pensadas pelos elaboradores visaram contribuir com ações destinadas à geração de ocupação e renda das famílias remanejadas para os conjuntos habitacionais construídos, conforme um dos objetivos propostos:

\begin{abstract}
"Realizar oficinas e/ou cursos de capacitação e qualificação profissional, proporcionandoacesso das famílias a atividades de ocupação e renda, que leve ao desenvolvimento econômico-financeiro que venha a contribuir para a sua fixação na área e a sustentabilidade das obras e serviços implantados" (COHAB, 2007, p.10).
\end{abstract}

A sustentabilidade é vista como objetivo a ser atingido para a manutenção e a fixação dos beneficiários aos conjuntos habitacionais, primeiramente, numa dimensão econômica, mas com sentido de tornar esses sujeitos plenamente adaptados ao novo ambiente de moradia, numa clara perspectiva social, onde a melhoria da qualidade de vida das famílias aparece como o objetivo final. Esta ideia tenta compatibilizar a necessidade de superação do quadro socioambiental problemático no espaço intraurbano com o desenvolvimento de uma política anticíclica de geração de emprego e renda, uma vez que também procura aproveitar a mão de obra local nas próprias obras executadas - ação contida na normativa de execução dos projetos - e, ao mesmo tempo, possibilitar alguma qualificação para a população beneficiária por meio dos cursos e oficinas ofertadas pelo PTTS.

"Na intenção de contribuirmos para o combate desta situação, apresentamos a presente proposta que está voltada à erradicação de palafitas na área do TABOQUINHA, onde de forma integrada e com a participação do beneficiário, serão desenvolvidas ações nas áreas, de saneamento, meio ambiente, habitação, educação, trabalho/renda, saúde, segurança, esporte, lazer e cultura. $[. . .]^{\prime \prime}$ 
"Pretendemos a partir da intervenção proposta, contribuir para a promoção de mudanças na realidade atual, onde as familias estão sobrevivendo em condições sub-humanas, localizadas em áreas insalubres e inadequadas para moradia" (COHAB, 2007, p. 7-8).

Nos termos do PTTS, a sustentabilidade reside em, além de "acabar com as palafitas na área do TABOQUINHA [...]", auxiliando na "[...] promoção de mudanças na realidade atual [...]", sem, no entanto, alterar o quadro de pobreza material estrutural das famílias, os inserindo naquilo que Lefebvre chama de espaço abstrato, numa tendência de continuação da atuação do Estado, via PAC, na reprodução de espaços para habitação contraditórios, como fotocópias de espaços-mercadorias, impondo controle social sobre as famílias a partir do remanejamento e da padronização monótona da tipologia que não tem relação com o entorno e com a própria cidade, no que Lefebvre (1973) chama de "periferias desurbanizadas, mas dependentes de cidade".

Nas entrevistas com os técnicos do Trabalho Social da COHAB/PA, ratificou-se o entendimento sobre a sustentabilidade como aspecto importante a ser considerado na execução das obras, mas sempre referente ao viés econômico, e, em primeiro lugar, à geração de ocupação e renda, ainda que de modo superficial, estando distantes quaisquer elementos ambientais. A adaptação das famílias tem primazia em relação às questões culturais ou relação dos sujeitos com o espaço construído:

"A perspectiva do trabalho técnico social é possibilitar ações que diminuam o impacto dessa transiç̧ão (da ocupação ao conjunto habitacional), principalmente no que diz respeito à melhoria da renda e condições de vida na nova residência. Muitas oficinas de artesanato, de panificação, de corte e costura, por exemplo, foram disponibilizadas para os beneficiários que buscaram nelas uma forma de melhorar sua renda, tudo isso ligado ao perfil socioeconômico que foi identificado [...] desse jeito, as familias conseguem uma forma de obtenção de sustento que antes não existia" (TS2).
As ações propostas pelo PTTS têm relevância dentro de um contexto de baixa qualificação percebida no perfil da população, embora não esteja conectada a ele claramente. O projeto não destina, por exemplo, qualquer atividade aos trabalhadores da pesca, considerados na análise do perfil socioeconômico como parcela significativa. Mesmo que tendo uma leitura sobre sustentabilidade mais aproximada ao viés socioeconômico, o Projeto não consegue fazer uma interpretação das necessidades da comunidade, neste aspecto. Desprezou-se, assim, a vivência da população e uma importante expressão relacionada a sua base material.

Nas entrevistas com os técnicos responsáveis pela elaboração e execução dos projetos físicos, destacou-se também o caráter inédito que trouxe o PAC em relação à destinação de aporte financeiro exclusivamente direcionado ao trabalho técnico social de forma a complementar à mudança das famílias para os conjuntos, o que também exprime a sustentabilidade de forma econômica. Conforme o Técnico TF1 destaca:

"A gente não pode falar mal do PAC. Pela primeira vez na história houve recurso exclusivo para um trabalho social, um trabalho que vem somar ao que o projeto físico elabora, de certo modo. No caso do Taboquinha, a mudança foi muito grande porque os locais onde as pessoas moravam era precário e a mudança para os blocos foi um grande avanço para as famililas, embora saibamos que ainda há muito o que melhorar nessa dinâmica tanto em relação ao projeto das unidades, quanto nas condições de vida das familias. Essas familias moravam em cima da água, na área do antigo lgararpé Cubatão. [...] A questão da água, da acessibilidade, da destinação do lixo foi resolvida. 0 PAC tem uma das melhores filosofias ambientais entre os programas já elaborados que eu conheço desde que eu entrei na COHAB, na década de 1970".

“O PAC foi um laboratório incrivel para nós [...] a amarração que as normativas têm na questão ambiental é muito importante" (TF2).

"O desafio era grande. 0 projeto continha uma praça para cada conjunto, mas como os recursos foram ficando sem 
atualização desde a aprovação, creio que apenas uma delas ficou como inicialmente deveria" (TF1).

Embora os elogios à estrutura do Programa sejam relevantes, sinalizando o início de uma nova abordagem frente aos processos de remanejamento e reassentamento urbanos, destinando recursos ao trabalho técnico social, há lacunas bastante significativas ainda não preenchidas na execução, como negação das vivências da população atendida, o tipo de espaço produzido, ausência de espaços de lazer, ausência de espaços de consumo, distanciamento em relação às práticas cotidianas anteriores, como fica evidente nas respostas dos beneficiários B8 e B11, respectivamente:

"Sobre o lazer acho até que piorou porque antes lá no Cubatão (ocupação) as crianças brincavam no campo de futebol que tinha lá. Aqui não tem nada. Disseram que ia ser construída uma praça, mas a única que tem nem é do Conjunto... As crianças brincam aqui fora, mas não acho seguro".

"Aqui não é ruim porque a gente não está mais em cima da água em casa de madeira, mas ficou tudo diferente. Nossos vizinhos foram pro Mestre Cardoso e a gente veio pra cá... A gente tinha uma vida lá e outra aqui. Em algumas coisas melhorou. Em outras não, mas a gente acaba dando um jeito. A gente ficou longe e acabou conhecendo outras pessoas. A verdade é que a gente se adapta em qualquer lugar se for preciso, né?"

Para Lefebvre (1973), o espaço tem um aspecto perceptível que pode ser apreendido por meio dos sentidos. Essa percepção constitui um componente integral de toda prática social. Ela compreende tudo que se apresenta aos sentidos; não somente a visão, mas a audição, o olfato, o tato e o paladar. Esse aspecto sensualmente perceptivo do espaço relaciona-se diretamente com a materialidade dos "elementos" que constituem o "espaço". No caso das famílias remanejadas os juízos de valor descritos são interpretações do espaço percebido que contém suas valorações sobre o novo espaço em oposição ao antigo, como "melhor" ou "pior", isto é, uma contraposição que define suas representações do espaço, nas passagens acima, relativizando os problemas ainda presentes em função do acesso à casa própria.

Nas entrevistas com os beneficiários é perceptível que estes veem a mudança para os conjuntos como positiva, sendo as unidades vistas como adequadas em comparação à ocupação onde residiam. A observação negativa mais apontada é o valor das contas de energia elétrica, como frisou B4. B6 destacou a importância das ações do trabalho técnico social:

"O conjunto é melhor que o lugar onde a gente morava, mas o que ficou difícil aqui é a conta da CELPA (concessionária de energia). Ficou muito difícil pagar a conta porque lá a gente pagava taxa e aqui o valor é alto. É um absurdo! [...] A gente sabe que vai sair da palafita e ir pra um lugar melhor, mas pra mim, as coisas pioraram por causa do meu trabalho porque sou costureira e a energia elétrica é importante".

O espaço não pode ser percebido enquanto tal sem ter sido concebido previamente em pensamento. A junção de elementos para formar um "todo" que é então considerado ou designado como espaço presume um ato de pensamento (LEFEBVRE, 1973). O espaço concebido, nesse caso, não consegue atender às necessidades dos beneficiários, principalmente no que diz respeito ao trabalho, o que vai de encontro às estratégias pensadas pelo PTTS para qualificar pessoas da comunidade, sem falar nas questões estruturais citadas em relação ao lazer, espaços de uso comum, às unidades habitacionais e ao acesso a serviços básicos.

B8 destacou que há consideração por parte dos beneficiários da importância da mudança de sua família para unidades habitacional, em relação à qualidade do ambiente construído, embora considere ainda distante do desejável como um bom espaço para viver, pois "[...] ainda tem muito problema. Problema com água, o lixo demora pra ser recolhido... Mas a gente não tem que reclamar, 
não. Hoje a gente vive num lugar nosso".

Outro aspecto importante para a análise é a associação entre a mudança de residência e o valor de troca que fica estabelecido após esta mudança, como fica claro na resposta de B11: "Muita gente já saiu daqui... Vendeu e foi pra outro lugar. Quando tinha fiscalização da COHAB não tinha tanta gente vendendo, alugando... Tem gente que ganha dinheiro".

Assim, as intervenções habitacionais do Projeto Taboquinha tendem a negar as vivências dos beneficiários, sobretudo, em função do tipo de espaço de moradia, tipo de espaço de lazer, o que reforça o entendimento destes espaços como abstratos que se contrapõem a espaços sociais, mais orgânicos no sentido das relações sociais neles estabelecidas. São espaços homogêneos, fragmentados, hierárquicos, que valorizam o quantitativo, o regulado, sem valor de uso, isto é, são espaços-produto.

O espaço vivido, a terceira dimensão da produção do espaço é a experiência vivida do espaço, resiste como resíduo nesse contexto. Essa dimensão significa o mundo assim como ele é experimentado pelos seres humanos na prática de sua vida cotidiana. No nosso caso, reside na experiência dos beneficiários, não mensurada pelo PTTS ou pelo projeto construtivo, mas que resiste quando B9 diz que "[...] fazemos duas festas por ano aqui que a gente já fazia no Cubatão: no Dia das Crianças e no Natal, quando a gente se reúne e é bem legal...". Um movimento que parte da tradição e da relação afetuosa entre os sujeitos que transcende a materialidade e congrega um sentido de comunhão. Tal como Lefebvre destaca o vivido: como a experiência prática que não se deixa exaurir. Sempre permanecendo como um excedente, um remanescente, o indizível, o que não é passível de análise, apesar de ser o mais valioso resíduo.

\section{Conclusões}

Não é possível pensar nos conjuntos habitacionais periféricos para remanejamento de famílias em situação de vulnerabilidade descolados da realidade e do sistema econômico que o produz e das implicações que essa produção traz consigo. Considerar a estrutura socioeconômica e as carências não apenas advindas dela é indispensável para entender como esses espaços habitacionais para os mais pobres são produzidos, como é o caso em estudo.

A sustentabilidade descrita no PTTS do Projeto Taboquinha é discursiva e deslocada da realidade atual das famílias na efetivação do projeto e no remanejamento, pois as ações se baseiam exclusivamente no aspecto econômico, mas com nenhum nexo com a vida material dos beneficiários. Embora o acesso à casa própria seja valorizado e as condições de habitação sejam melhores em relação à precariedade da ocupação irregular e vulnerável habitada anteriormente, na categoria lazer há uma lacuna não preenchida que denota, além da desconsideração da necessidade de espaços e relações, a reprodução de uma lógica pautada na homogeneização, na monotonia e sem conexão com as vivências da população atendida.

O Programa impõe tipo de espaço de moradia, tipo de espaço de lazer, tipo de consumo. São espaços abstratos que se contrapõem a espaços sociais (do comércio, das feiras, dos campos de futebol, dos ambulantes). Cria-se um espaço que, entre outros problemas, valoriza o quantitativo, o regulado, sem valor de uso, o espaço-produto, como fotocópia de um espaço-mercadoria.

Obviamente, os limites do trabalho ora exposto são estabelecidos pela análise de apenas uma das três categorias destacadas por Lefebvre, como essenciais para a consideração do cotidiano, sendo este artigo ainda uma aproximação superficial com carências de aprofundamento nas outras e na gama de encadeamentos que o tema suscita.

\section{Referências bibliográficas}

ABIKO, A.; COELHO, L. O. Urbanização de Favelas:

procedimentos de gestão. Porto Alegre: ANTAC, 2009.

ACSELRAD, $H$. Discursos da Sustentabilidade Urbana. Revista Brasileira de Estudos Urbanos e

Regionais, número 1, 1999. 
ACSELRAD, H. Desregulamentação, Contradições Espaciais e Sustentabilidade Urbana. Anais do XI Encontro Nacional de Pesquisa em PósGraduação e Pesquisa em Planejamento Urbano e Regional, ANPUR. Salvador: UFBA, 2005.

ACSELRAD, H. A Duração das Cidades: sustentabilidade e Risco nas Políticas Urbanas. 2a ed. Henri Acselrad (Org.). Rio de Janeiro: Editora DP\&A/ Lamparina, 2009.

BRASIL. Estatuto das Cidades. Lei Federal n. 10.257/2001. Congresso Nacional, 2001.

BRASIL. Ministério das Cidades. Experiências em Habitação de Interesse Social no Brasil. ARRUDA, A.M.V; CUNHA, E.M.P; MEDEIROS, Y. (Org.). Brasília: Secretaria Nacional de Habitação, 2008.

BRASIL. Ministério das Cidades. Programa de Aceleração do Crescimento. Disponível em http:// www.pac.gov.br/ Acesso em 25 de novembro de 2018.

BRASIL. Ministério das Cidades. Relatório de Gestão do FNHIS. Secretaria Nacional de Habitação, 2010.

CARDOSO, A. C. Uma discussão sobre Políticas Públicas Relacionadas à Habitação e à Cidade e sua Relação com os Programas Implantados Durante a Segunda Gestão do Governo Lula. Natal: Departamento de Políticas Públicas da UFRN, 2009

CARDOSO, A. C.; VENTURA NETO, R. A Evolução Urbana de Belém: trajetória de Ambiguidades e Conflitos Socioambientais. Cadernos Metrópole. São Paulo, v. 15, n. 29, p. 55-75, jan/jun 2013.

CASTRO, M. O. Os programas Habitacionais de Interesse Social e sua Atuação na Região Metropolitana de Belém: a Espacialização das Ações na Contramão do Direito à Cidade. Dissertação (Mestrado). Universidade Federal do Pará, Instituto de Filosofia e Ciências Humanas, Programa de Pós-Graduação em Geografia, Belém, 2013.
CORREAA, R. L. Trajetórias geográficas. Rio de Janeiro: Bertrand Brasil, 1997.

COSTA, H. S. M. Desenvolvimento Urbano Sustentável: uma contradição de termos? Revista Brasileira de Estudos Urbanos e Regionais, n. 2, 1999.

HARVEY, D. A Produção Capitalista do Espaço. São Paulo, Annablume, 1981.

HARVEY, D. A Justiça Social e a Cidade. São Paulo: Hucitec, 1982.

IBGE. Instituto Brasileiro de Geografia e Estatística. Aglomerados Subnormais, Informações Territoriais. Primeiros resultados. Rio de Janeiro, 2010

IPEA/IDESP. Relatório de Pesquisa 1.2: Análise Comparativa das Funções Públicas de Interesse Comum. Região Metropolitana de Belém. Brasília: 2013.

JACOBI, P. Impactos socioambientais urbanos - do risco à busca da sustentabilidade. In: MENDONÇA, F. (org.) Impactos Socioambientais Urbanos. Curitiba: Editora UFPR, 2004. 330 p.

JAPIASSU, H. Interdisciplinaridade e Patologia do saber. Rio de Janeiro: Imago, 1976.

CEF - Caixa Econômica Federal. Selo Casa Azul. Boas práticas para habitação mais sustentável. São Paulo: Páginas \& Letras - Editora e Gráfica, 2010

LEÃO, M. S.; LIMA, J. J. F. Reassentamento involuntário em projetos de saneamento em Belém do Pará. Revista e-metrópolis. Número 25, ano 7, 2017.

LEFEBVRE, H. A Reprodução das Relações de Produção. Tradução: Antonio Ribeiro e M. do Amaral. Porto: Publicações Escorpião - Cadernos O Homem e a Sociedade, 1973.

LEFEBVRE, H. Critique de la Vie Quotidienne I: Introduction. Paris: Arche, 1978. 
LEFEBVRE, H. The Production of Space. Tradução Roberta Tavares. Blackwell Publishing (EUA), 1991.

LEFEBVRE, H. O direito à cidade. São Paulo: Centauro Editora, 2004.

LEFEBVRE, H. Ecologia, Capital e Cultura: a territorialização da racionalidade ambiental. Petrópolis: Editora Vozes, 2009.

\section{LEITÃO, K. O. A Dimensão Territorial do Programa} de Aceleração do Crescimento: o estudo sobre o PAC no estado do Pará e o lugar que ele reserva à Amazônia no desenvolvimento do País. Tese (Doutorado). Programa de Pós-Graduação em Arquitetura e Urbanismo da Universidade de São Paulo, 2009.

LIMA, J. J. F.; LEÃO, M. S.; LIMA, A. P. Limitações na gestão do PAC urbanização: o caso do Projeto PAC Taboquinha, Belém do Pará. Anais do XVII Encontro Nacional ANPUR. São Paulo, 2017.

LIMA, J. J. F. et al. A questão habitacional na Região Metropolitana de Belém. In: CARDOSO, A. L. (org.). Habitação Social nas Metrópoles Brasileiras: uma avaliação das políticas habitacionais em Belém, Belo Horizonte, Porto Alegre, Recife, Rio de Janeiro e São Paulo no final do século XX. Porto Alegre: ANTAC, 2007 (Coleção Habitare).

MARICATO, E. Metrópole na periferia do capitalismo: ilegalidade, desigualdade e violência. São Paulo: Hucitec, 2005.

MARICATO, E. Metrópole, Legislação e Desigualdade. Revista Estudos Avançados, 2003. Disponível em: <http://www.scielo.br/pdf/ea/v17n48/v17n48a13. pdf >. Acesso em: 15 nov. 2018.

MARICATO, E. As Tragédias Urbanas: desconhecimento, ignorância ou cinismo? São Paulo: GEOUSP, 2009.

MARICATO, E. O impasse da Política Urbana no Brasil. São Paulo: Editora Vozes, 2011.
MCIDADES. Ações Integradas de Urbanização de Assentamentos Precários - Edição Bilíngue. Brasília/São Paulo: Ministério das Cidades/Aliança de Cidades, 1a edição/2010.

MPOG. Ministério do Planejamento, Orçamento e Gestão. 4 ${ }^{\circ}$ Balanço do PAC (Pará) 2015-2018. Brasília: MPOG, 2016.

MPOG. Ministério do Planejamento, Orçamento

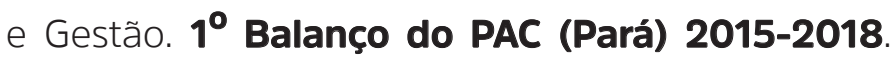
Brasília: MPOG, 2015.

MPOG. Ministério do Planejamento, Orçamento e Gestão. $1^{0}$ Balanço do PAC2 (2011-2014). Brasília: MPOG, 2014.

MPOG. Ministério do Planejamento, Orçamento e Gestão. 11 $^{\circ}$ Balanço do PAC2. Brasília: MPOG, 2014.

PARÁ. Companhia Executiva de Habitação do Pará. Balanço das Ações de 2012. Slides Ppt. Belém: COHAB, 2011.

PARÁ. Companhia Executiva de Habitação do Pará. Projeto de Trabalho Técnico Social do Projeto PAC Taboquinha. Belém: COHAB, 2007. Inédito.

ROLNIK, R. (Org.) Como Produzir Moradia bem Localizada com Recursos do Programa Minha Casa Minha Vida? Implementando os instrumentos do Estatuto da Cidade. Brasília: Ministério das Cidades, 2010.

ROLNIK, R. Pactuar o Território: desafio para a gestão de nossas cidades. Publicado em 01/09/2008. Disponível em <http://raquelrolnik. wordpress.com/2008/09/01/desafios-da-gestaourbana/>. Acesso em: 09 de agosto de 2018.

ROLNIK, R.; CYMBALISTA, R.; NAKANO, K. Solo urbano e habitação de interesse social: a questão fundiária na política habitacional e urbana do país. Revista de Direito da ADVOCEF, v. 1, p. 123-158, 2011.

SOUZA, M. J. L. Desenvolvimento urbano: a 
problemática renovação de um "conceito" -problema. Revista Território, ano 3, número 5, 1998.

SOUZA, M. J. L. Mudar a cidade: uma introdução crítica ao planejamento e à gestão urbanos. $4^{a}$ ed. Rio de Janeiro: Editora Bertrand Brasil, 2002.

TRINDADE JR., S.-C. C. A Cidade Dispersa: os novos espaços de assentamentos em Belém e a reestruturação metropolitana. 1998. Tese (Doutorado) - Faculdade de Filosofia, Letras e Ciências Humanas, Universidade de São Paulo, São Paulo, 1998.

TRINDADE JR., S.-C. C. Formação metropolitana de Belém (1960-1997). Belém: Paka-Tatu, 2016.

UN-HABITAT. Planning sustainable cities. Global report on human settlements 2009. London, UK: United Nations Human Settlements Programme (UN-HABITAT), 2009.

UN-HABITAT. Forced Eviction: Global crisis, Global solutions. A Review of the status of Forced Evictions Globally through the Work of the Advisory Group on Forced Evictions, Un-Habitat and Other International Actors. United Nations Human Settlements Programme (UN-HABITAT), Nairobi, 2011.

UN-HABITAT. Sustainable housing for sustainable cities a policy framework for developing countries. Nairobi, Kenya: United Nations Human Settlements Programme (UN-HABITAT), 2012.

UNCSD. Rio+20 - United Nations Conference on Sustainable Development. Disponível em: <www. uncsd2012.org >Acesso em: maio 2018.

VILLAÇA, F. Espaço intra-urbano no Brasil. São Paulo: Studio Nobel: FAPESP: Lincoln Institute, 2001. 